\title{
Fabrication and in vitro release behavior of a novel antibacterial coating containing halogenated furanone-loaded poly(L-lactic acid) nanoparticles on microarc-oxidized titanium
}

\author{
This article was published in the following Dove Press journal: \\ International Journal of Nanomedicine \\ 6 November 2012 \\ Number of times this article has been viewed
}

\section{Yicheng Cheng' \\ Jiang $W^{\prime}$ \\ Bo Gao' \\ Xianghui Zhao ${ }^{2}$ \\ Junyan Yao ${ }^{3}$ \\ Shenglin Mei ${ }^{1}$ \\ Liang Zhang ${ }^{4}$ \\ Huifang Ren' \\ 'Department of Prosthodontics, School of Stomatology, Fourth Military Medical University, \\ ${ }^{2}$ Institute of Neuroscience, School of Basic Medicine, Fourth Military Medical University, ${ }^{3}$ Department of Applied Chemistry, School of Science, Northwestern Polytechnical University, ${ }^{4}$ Department of Orthodontics, School of Stomatology, Fourth Military Medical University, Xi'an, China}

Yicheng Cheng and Jiang Wu contributed equally to this work

Correspondence: jiang Wu Department of Prosthodontics, School of Stomatology, Fourth Military Medical University, I45, West Changle Road,

Xi'an 710032, People's Republic of China

Tel +86298477 6469

Fax +862984776469

Email wujiang@fmmu.edu.cn

Bo Gao

Department of Prosthodontics, School of Stomatology, Fourth Military Medical University, No. 145, West Changle Road, Xi'an 7I 0032, People's Republic of China $\mathrm{Tel}+862984776469$

Fax +862984776469

Email gaobo@fmmu.edu.cn
Background: Dental implants have become increasingly common for the management of missing teeth. However, peri-implant infection remains a problem, is usually difficult to treat, and may lead eventually to dental implant failure. The aim of this study was to fabricate a novel antibacterial coating containing a halogenated furanone compound, ie, (Z-)-4-bromo-5(bromomethylene)-2(5H)-furanone (BBF)-loaded poly(L-lactic acid) (PLLA) nanoparticles on microarc-oxidized titanium and to evaluate its release behavior in vitro.

Methods: BBF-loaded PLLA nanoparticles were prepared using the emulsion solventevaporation method, and the antibacterial coating was fabricated by cross-linking BBF-loaded PLLA nanoparticles with gelatin on microarc-oxidized titanium.

Results: The BBF-loaded PLLA nanoparticles had a small particle size (408 $\pm 14 \mathrm{~nm}$ ), a low polydispersity index $(0.140 \pm 0.008)$, a high encapsulation efficiency $(72.44 \% \pm 1.27 \%)$, and a fine spherical shape with a smooth surface. The morphology of the fabricated antibacterial coating showed that the BBF-loaded PLLA nanoparticles were well distributed in the pores of the microarc oxidation coating, and were cross-linked with each other and the wall pores by gelatin. The release study indicated that the antibacterial coating could achieve sustained release of BBF for 60 days, with a slight initial burst release during the first 4 hours.

Conclusion: The novel antibacterial coating fabricated in this study is a potentially promising method for prevention of early peri-implant infection.

Keywords: antibacterial, coating, halogenated furanone, nanoparticles, microarc oxidation, sustained release

\section{Introduction}

Dental implants are the most innovative and superior treatment used in dentistry, and are becoming increasingly one of the major treatment modalities for replacement of missing teeth. ${ }^{1,2}$ The success rate for dental implants has been frequently reported to be as high as $90 \%-95 \%$ for both partially and completely edentulous patients in longitudinal studies. ${ }^{3,4}$ Despite this high success rate, many studies have demonstrated that dental implants do sometimes fail. ${ }^{5,6}$ Peri-implant infection, which may be categorized as early or late, is reported to be one of the most important causes of dental implant failure. $^{7-9}$ Early infection occurs before osseointegration, while late infection occurs after prosthetic rehabilitation. Surgical trauma and bacterial invasion during and after implant insertion are the primary causes of early infection. ${ }^{10}$ Late infection seems to be related to peri-implantitis. ${ }^{11}$ Bacteria adhering to the surface of the implant and forming 
biofilm play a pivotal role in early peri-implant infection. ${ }^{12,13}$ Although various measures, such as thorough disinfection and stringent aseptic operation, have been proposed to mitigate bacterial contamination, there is still evidence that bacterial invasion occurs after dental implant surgery. ${ }^{9}$ Additionally, over 300 species of bacteria are present in the oral cavity, each region of which is home to a characteristic assemblage of microbial flora. ${ }^{14}$ Bacteria on the mucosa and adjacent teeth can invade the peri-implant soft tissue, and may potentially progress deeper into the bone and undermine the osseointegration process. ${ }^{10}$ Because there is still no good means available to eliminate peri-implant infection completely after it has occurred, it is imperative to explore effective ways to prevent bacterial invasion. Fabricating antibacterial coatings on titanium implants is an important strategy to prevent early periimplant infection, which inhibits initial bacterial adhesion. ${ }^{15}$ Therefore, various antibacterial coatings containing many kinds of antibacterial have been designed. However, concerns about the susceptibility of bacteria in the oral cavity to antibacterial and drug resistance of bacteria ${ }^{16,17}$ have encouraged the search for new effective antibacterial strategies. Another matter of concern has been the antibacterial release time. ${ }^{15}$

In recent years, halogenated furanones, a class of secondary metabolites originally extracted from the red algae, Delisea pulchra, have been demonstrated to have antimicrobial properties that inhibit microbial colonization on the algal surface. ${ }^{18,19}$ Subsequently, a variety of analogs of the natural halogenated furanones have been synthesized and evaluated for their efficacy. These compounds have been demonstrated to have potent antimicrobial activity against a great number of Grampositive and Gram-negative bacteria and to inhibit biofilm formation..$^{20,21}$ Halogenated furanone compounds can control multicellular behavior in various microbial species induced by autoinducer- 1 and autoinducer- $2,{ }^{22}$ which are used for cell-to-cell communication to control production and secretion of virulence factors, proteolytic activity, carbohydrate metabolism, and biofilm formation. ${ }^{23}$ The novel nature of their mechanisms of action would allow these new antimicrobials to be effective against bacteria that are currently antibiotic-resistant. ${ }^{24}$ In spite of the inhibitory effects on microbial biofilm formation, reports of the effects on eukaryotic cell viability and toxicity of halogenated furanone compounds are scarce, and reports on genotoxic effects seem to be lacking. ${ }^{25,26}$ Owing to their advantages, many researchers have suggested that halogenated furanone compounds would potentially be ideal antibacterial agents on implants for preventing biofilm infection. ${ }^{27,28}$ However, there have been few relevant reports on how to use halogenated furanone compounds in implants until now.
During the past decade, considerable research efforts have aimed at developing controlled-release systems for several drugs (eg, anesthetics, antibiotics, antitumoral drugs, proteins) from biodegradable polymers such as poly(D, L-lactic acid) (PLA), poly(D, L-lactide-co-glycolide), and poly(-caprolactone) ${ }^{29,30}$ Among them, PLA has been widely developed as a microsphere/nanoparticle carrier due to its desirable biocompatible and biodegradable properties. PLA is also approved by the US Food and Drug Administration for clinic use. The simplest and most commonly employed method for preparing microspheres/nanoparticles is oil-inwater emulsion-solvent evaporation, which shows good encapsulation efficiency of water-insoluble compounds.

However, being bioinert, the integration of titanium implants in bone is not in good condition. Previous studies have suggested that the rate and extent of osseointegration is mainly determined by the properties of the implant surface. ${ }^{31}$ Many efforts have been made to modify the composition and topography of the implant surface and thereby achieve improved osseointegration. ${ }^{31,32}$ Current trends include use of endosseous dental implant surfaces embellished with nanostructured topography. ${ }^{33,34}$ Microarc oxidation is a commonly used surface modification technique for producing an inorganic glass-ceramic-like coating on the titanium surface, for the purpose of providing corrosion-resistance and wear-resistance or various functional properties. ${ }^{35,36}$ Previous studies have showed that microarc oxidation helps to form a biologically active bone-like apatite layer on titanium, which may improve the biological response. ${ }^{37}$ Moreover, the microarc oxidation coating has a porous surface, with pores $1-5 \mu \mathrm{m}$ in diameter at regular intervals, providing space for adhesion of nanoparticles.

The purpose of the current study was to prepare poly(Llactic acid) (PLLA) nanoparticles containing a halogenated furanone compound, (Z-)-4-bromo-5-(bromomethylene)$2(5 \mathrm{H})$-furanone $(\mathrm{BBF})$, and then fabricate a new antibacterial coating containing BBF-loaded PLLA nanoparticles on microarc-oxidized titanium and evaluate the release behavior in vitro, in order to provide a new method for prevention of early peri-implant infection.

\section{Materials and methods Materials}

BBF ( $\geq 97.0 \%$ ), PLLA (number average 99,000, average molecular weight 152,000), poly(vinyl alcohol) (PVA, molecular weight 89,000-98,000) and gelatin powder (type A) were purchased from Sigma-Aldrich Chemicals (St Louis, $\mathrm{MO})$. The chemical structure of BBF is shown in Figure 1. 


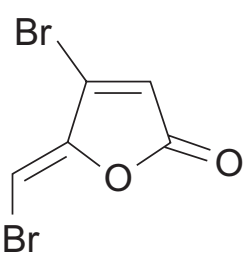

Figure I Chemical structure of (Z-)-4-bromo-5-(bromomethylene)-2(5H)-furanone.

Commercially pure titanium (grade 2) was provided by Xi'an Aerospace New Material Co, Ltd (Xi'an, China). Methanol (high-performance liquid chromatography grade) and other chemicals and solvents (analytical grade) were supplied by Tianjin Fuchen Chemical Factory (Tianjin, China).

\section{Preparation of BBF-loaded PLLA nanoparticles}

BBF-loaded PLLA nanoparticles were prepared using the classical oil-in-water emulsion solvent-evaporation method. The procedure is schematically shown in Figure 2A. Briefly, the oil phase containing $15 \mathrm{mg}$ of $\mathrm{BBF}$ was added to $2 \mathrm{~mL}$ of dichloromethane in which was dissolved $100 \mathrm{mg}$ of PLLA $(5 \% \mathrm{w} / \mathrm{v})$ under sonication for 5 minutes. This oil phase was added to $40 \mathrm{~mL}$ of $1 \%$ (w/v) PVA aqueous solution, which was prepared by heating and stirring during addition of PVA. The mixed solution was then probe-sonicated using a Sonifier Cell
Disrupter (JY98-IIIN, Ningbo Xingzhi Biological Technology Co, Ltd, China) in an ice bath to produce an oil-in-water emulsion. The intensity and duration of the sonication process were $300 \mathrm{~W}$ and 200 seconds, respectively. The resulting emulsion was stirred using a magnetic stirring device (90-1, Zhengzhou KaiPeng Experiment Instrument Co, Ltd, China) for 6 hours at $25^{\circ} \mathrm{C}$ under reduced pressure to evaporate the dichloromethane completely. After preparation, the nanoparticles were collected by centrifugation at $12,000 \mathrm{rpm}$ for 20 minutes. The collected nanoparticles were then washed three times with distilled water in an ultrasonic bath at $37^{\circ} \mathrm{C}$, isolated by centrifugation, and finally freeze-dried.

\section{Characterization of BBF-loaded PLLA nanoparticles}

\section{Size, size distribution, and surface morphology}

The mean particle size, size distribution, and polydispersity index of the nanoparticles were assessed by dynamic light scattering using a particle size analyzer (SALD-7101, Shimadzu Corporation, Tokyo, Japan) at $25^{\circ} \mathrm{C}$. For a typical experiment, $10 \mathrm{mg}$ of BBF-loaded PLLA nanoparticles were sonicated to suspend in $5 \mathrm{~mL}$ of distilled water and then analyzed using the particle size analyzer. Each value reported was the mean \pm standard deviation for three replicate samples. The shape and surface morphology of the nanoparticles were
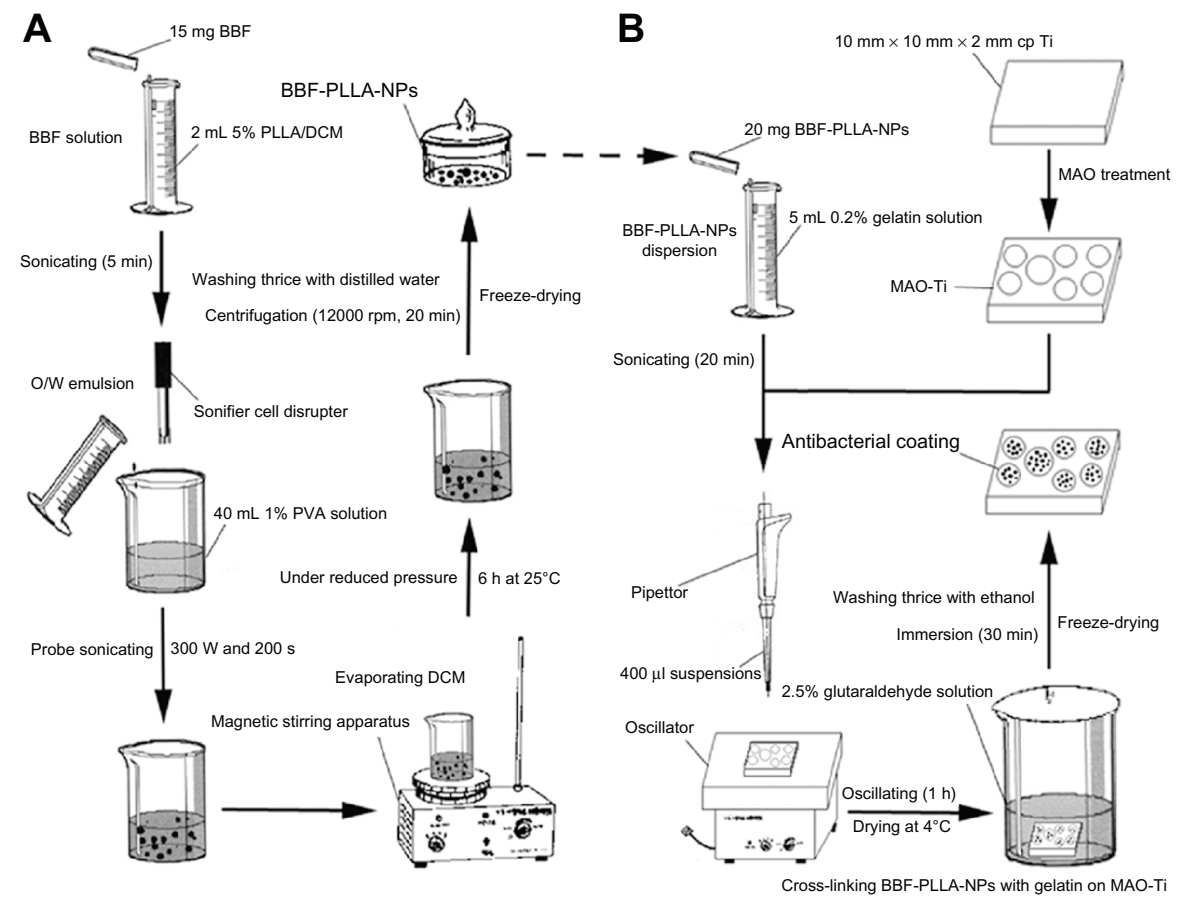

Figure 2 Schematic presentation of the preparation of BBF-loaded PLLA nanoparticles and the fabrication of antibacterial coating containing BBF-loaded PLLA nanoparticles on MAO-Ti. (A) Preparation of BBF-loaded PLLA nanoparticles. (B) Fabrication of antibacterial coating containing BBF-loaded PLLA nanoparticles on MAO-Ti.

Abbreviations: BBF, (Z-)-4-bromo-5-(bromomethylene)-2(5H)-furanone; DCM, dichloroethane; PLLA, poly(L-lactic acid); NPs, nanoparticles; MAO-Ti, microarc-oxidized titanium; PVA, poly (vinyl alcohol); O/W, oil/water. 
observed by scanning electron microscopy (SEM, S-4800, Hitachi Co, Japan).

\section{Determination of drug incorporation}

The amount of drug incorporated into the nanoparticles was determined by high-performance liquid chromatography (Waters, Milford, MA), using a reverse phase Lichrospher C18 column (pore size, $5 \mu \mathrm{m}, 250 \mathrm{~mm} \times 4.6 \mathrm{~mm}$, Diamonsil, Dikma Technologies Inc, Lake Forest, CA). Next, $5 \mathrm{mg}$ of freeze-dried BBF-loaded PLLA nanoparticles was dissolved in $1 \mathrm{~mL}$ of dichloromethane and stirred after addition of $10 \mathrm{~mL}$ of methanol to precipitate the polymer preferentially. The precipitate was removed using a membrane filter. The solvent was then evaporated until dry with a nitrogen stream, followed by addition of $10 \mathrm{~mL}$ of methanol/water mixture $(75 / 25, \mathrm{v} / \mathrm{v})$. The clear solution obtained was put into a vial for detection of the BBF concentration using high-performance liquid chromatography. The mobile phase consisted of a mixture of methanol/water $(75 / 25, \mathrm{v} / \mathrm{v})$ and the flow rate was $1.0 \mathrm{~mL}$ per minute. The column effluent was detected at $286.0 \mathrm{~nm}$ using a variable wavelength detector with a column temperature of $30^{\circ} \mathrm{C}$. The experiments were performed in triplicate.

Drug incorporation was expressed both as actual drug loading (w/w) and encapsulation efficiency (\%), represented by equations (1) and (2), respectively, as:

$$
\begin{aligned}
& \text { Actual drug loading }(\mathrm{w} / \mathrm{w}) \\
& =\frac{\text { Mass of drug in nanoparticles }}{\text { Mass of nanoparticles }}
\end{aligned}
$$

Encapsulation efficiency (\%)

$$
=\frac{\text { Mass of drug in nanoparticles } \times 100 \%}{\text { Mass of initial drug used }}
$$

\section{In vitro $B B F$ release study}

The release study for BBF-loaded PLLA nanoparticles was performed using the dialysis bag diffusion method. First, $20 \mathrm{mg}$ of freeze-dried BBF-loaded PLLA nanoparticles (containing about $2.04 \mathrm{mg} \mathrm{BBF}$ ) was suspended in $5 \mathrm{~mL}$ of phosphate-buffered saline (containing $\mathrm{NaCl} 8 \mathrm{~g} / \mathrm{L}, \mathrm{KCl}$ $0.2 \mathrm{~g} / \mathrm{L}, \mathrm{Na}_{2} \mathrm{HPO}_{4} 1.44 \mathrm{~g} / \mathrm{L}$, and $\mathrm{KH}_{2} \mathrm{PO}_{4} 0.24 \mathrm{~g} / \mathrm{L}$, stabilized with sodium azide $0.2 \mathrm{~g} / \mathrm{L}, \mathrm{pH} 7.4$ ) and transferred to a dialysis bag (molecular weight cutoff $3500 \mathrm{~g} / \mathrm{mol}$, Shanghai Green Bird Science and Technology Development Co, Ltd, Shanghai, China). This bag was introduced into $100 \mathrm{~mL}$ of phosphate-buffered saline, with continuous gentle magnetic stirring at $37^{\circ} \mathrm{C}$ under sink conditions. At predetermined time intervals, $1 \mathrm{~mL}$ aliquots were withdrawn and replaced with the same volume of fresh buffer. All samples were taken for analysis of BBF concentration, which was first extracted with $1 \mathrm{~mL}$ of dichloromethane, followed by evaporating until dry using a nitrogen stream, and $10 \mathrm{~mL}$ of a methanol/water $(75 / 25, v / v)$ mixture was then added. High-performance liquid chromatography analysis was carried out as described in the previous section. Next, $2.04 \mathrm{mg}$ of BBF powder was examined under the same conditions for comparison. The experiments were performed in triplicate. Additionally, the morphology of the BBF-loaded PLLA nanoparticles in the dialysis bags was observed by SEM at predetermined time intervals to investigate the process of degradation.

\section{Preparation of commercially pure titanium specimens and microarc oxidation}

Plate specimens $(10 \mathrm{~mm} \times 10 \mathrm{~mm} \times 2 \mathrm{~mm})$ were used in this study. All the specimens were mechanically ground using various grades of silicon carbide paper (80-1200 grit), and then ultrasonically cleaned in ethanol, rinsed with water, and air-dried. Microarc oxidation was carried out in an aqueous electrolytic solution containing $0.04 \mathrm{M} \beta$-glycerophosphate sodium and $0.2 \mathrm{M}$ calcium acetate, using a pulsed direct current power supply (microarc oxidation equipment was designed and manufactured by Xi'an University of Technology, Xi'an, China). The applied voltage, frequency, duty cycle, and oxidizing time were $300 \mathrm{~V}, 600 \mathrm{~Hz}, 8.0 \%$, and 5 minutes, respectively. ${ }^{38}$ The microarc-oxidized titanium specimens were then rinsed with distilled water and air-dried immediately. The surface morphology of the specimens before and after microarc oxidation was observed by SEM. The surface phase composition of the oxide layer formed by the microarc oxidation process was analyzed by $\mathrm{x}$-ray diffraction (XRD-7000S, Shimadzu Corporation, Tokyo, Japan).

\section{Fabrication of antibacterial coating containing BBF-loaded PLLA nanoparticles on microarc-oxidized titanium}

The antibacterial coating was achieved by cross-linking the BBF-loaded PLLA nanoparticles with gelatin on microarcoxidized titanium..$^{39}$ The procedure is schematically shown in Figure 2B. In brief, $20 \mathrm{mg}$ of BBF-loaded PLLA nanoparticles were sonicated for 20 minutes to disperse them in $5 \mathrm{~mL}$ of $0.2 \%$ gelatin solution (w/v), from which $400 \mu \mathrm{L}$ suspensions were dropped onto the microarc-oxidized titanium. The microarc-oxidized titanium specimen was then oscillated on an oscillator (HY-2, Hangzhou Huier Experiment Instrument Co, Ltd, China) for one hour to enable the nanoparticles to 
penetrate the pores on the surface of the microarc-oxidized titanium. After oscillating, the microarc-oxidized titanium specimen was dried at $4{ }^{\circ} \mathrm{C}$, followed by immersion in $2.5 \%$ (w/v) glutaraldehyde solution for 30 minutes to cross-link the gelatin. Finally, the microarc-oxidized titanium specimen was washed with ethanol three times to remove the remaining glutaraldehyde and freeze-dried. The surface morphology of the antibacterial coating containing BBF-PLLA nanoparticles on microarc microarc-oxidized titanium was observed by SEM.

\section{In vitro study of BBF release from the antibacterial coating}

Release of BBF from the antibacterial coating was performed by placing one BBF-PLLA nanoparticle-coated microarcoxidized titanium specimen with $5 \mathrm{~mL}$ of phosphate-buffered saline in a dialysis bag (molecular weight cutoff $3500 \mathrm{~g} / \mathrm{mol}$ ). This bag was then introduced into $20 \mathrm{~mL}$ of phosphatebuffered saline with continuous gentle magnetic stirring at $37^{\circ} \mathrm{C}$. At predetermined time intervals, $1 \mathrm{~mL}$ aliquots were withdrawn and replaced with the same volume of fresh buffer. The BBF concentration in phosphate-buffered saline was measured according to the methods previously described. The experiments were performed in triplicate. The surface morphology of the antibacterial coating immersed in phosphate-buffered saline was also observed by SEM at predetermined time intervals to investigate the process of degradation.

\section{Results}

\section{Preparation and characterization of BBF-loaded PLLA nanoparticles}

\section{Size, size distribution, and surface morphology}

BBF-loaded PLLA nanoparticles were successfully prepared using the oil-in-water emulsion solvent-evaporation method. Particle size measured by dynamic light scattering revealed that the BBF-loaded PLLA nanoparticles had a mean particle size of $408 \pm 14 \mathrm{~nm}$. Figure 3 shows a narrow size distribution with a polydispersity index of $0.140 \pm 0.008$. A fine dispersion with long-term nanoparticle stability should have a narrow size distribution and a low polydispersity index, which is defined as the log normal distribution width of the particle diameter. Particle size can be controlled by altering several experimental parameters, such as polymer concentration, intensity and duration of sonication, and the volume ratio of the aqueous and organic phases.

The surface morphology of BBF-loaded PLLA nanoparticles is shown in Figure 4. All nanoparticles were spherical

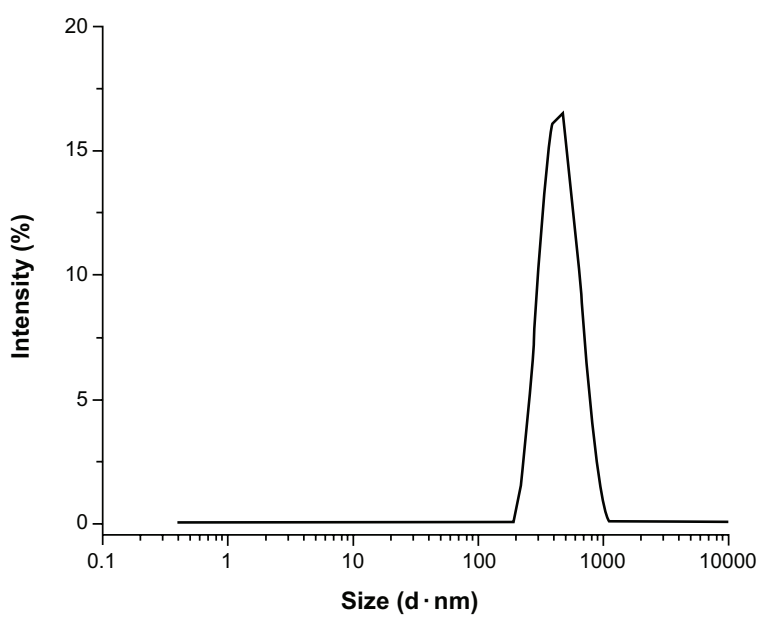

Figure 3 Size distribution of BBF-loaded PLLA nanoparticles. Abbreviations: BBF, (Z-)-4-bromo-5-(bromomethylene)-2(5H)-furanone; PLLA, poly(L-lactic acid).

in shape without any aggregation or adhesion (Figure 4A). The particle size distribution was well proportioned and in good agreement with the result measured by dynamic light scattering. Moreover, the BBF-loaded PLLA nanoparticles had a smooth surface, on which no pores and cracks were observed at high magnification (Figure 4B). Surface morphology is a crucial property for microspheres/nanoparticles, given that in vitro release experiments have shown that the initial burst from a smooth surface is less than that from a rough surface. ${ }^{40}$

\section{Drug incorporation}

Drug loading (w/w) and encapsulation efficiency (\%) of BBF determined by high-performance liquid chromatography analysis of the prepared PLLA nanospheres were $0.102 \pm 0.002 \mathrm{mg} / \mathrm{mg}$ and $72.44 \% \pm 1.27 \%$, respectively. The high encapsulation efficiency was probably due to the high affinity and solubility of BBF in the organic solvent and low solubility in the aqueous phase, which would consequently reduce the possibility of drug loss by diffusion during preparation of the nanospheres. Therefore, a large amount of BBF was successfully encapsulated in the PLLA nanospheres. Encapsulation efficiency can be affected by many factors, including the molecular weight of the polymer, particle size, and the mass ratio of drug and polymer.

\section{In vitro release study of BBF from BBF-loaded PLLA nanoparticles}

Figure 5 showed the in vitro release profiles for BBF from BBF-loaded PLLA nanoparticles and BBF powder. Experimental points over the complete time assay are shown in Figure 5A, and the first 24 hours in the release study are 


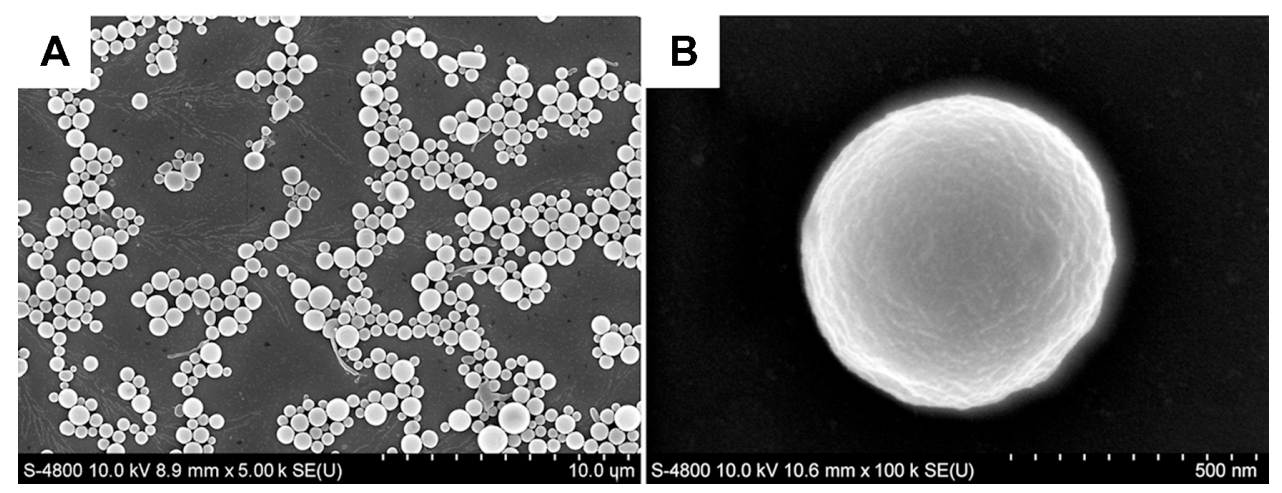

Figure 4 Scanning electron microscopic images of BBF-loaded PLLA nanoparticles. (A) BBF-loaded PLLA nanoparticles at low magnification. (B) BBF-loaded PLLA nanoparticles at high magnification.

Abbreviations: BBF, (Z-)-4-bromo-5-(bromomethylene)-2(5H)-furanone; PLLA, poly(L-lactic acid).

shown in Figure 5B. The in vitro release profiles for BBF from BBF-loaded PLLA nanoparticles showed a biphasic release pattern, namely an initial burst release and a more continuous slow release. The initial burst release showed that $15.4 \%$ of the accumulated BBF was released from the nanoparticles at the first sampling time of 6 hours. The burst effect is normally attributable to release of drug that is adsorbed or close to the surface of the nanoparticles, which is known to be permeable to water. ${ }^{41}$ In the second stage, release of BBF from nanoparticles was typically sustained and dependent on degradation of the polymer matrix and drug diffusion, which is a slower process. As time progressed, the nanoparticles were degraded, resulting in diffusion of water into their core and BBF diffusing into that water. The results obtained in the sustained release period show that $74.5 \%$ of the accumulated BBF was released slowly during the next 45 days. In the control group, $92.7 \%$ of BBF was released from the BBF powder in the first 18 hours.

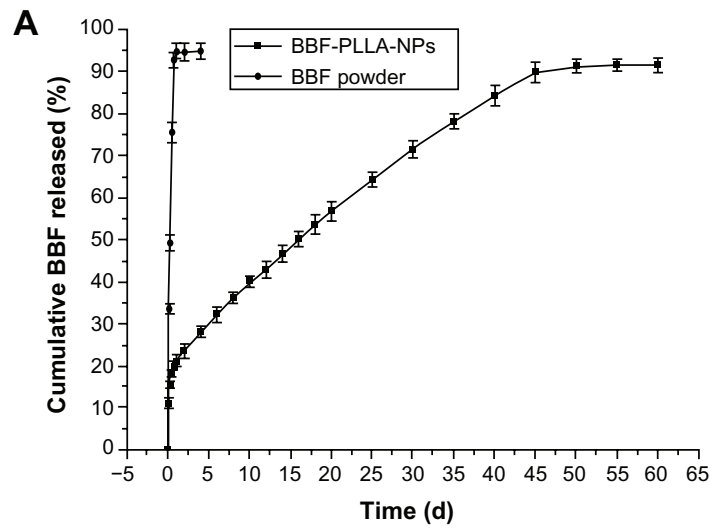

The degradation process for BBF-loaded PLLA nanoparticles in phosphate-buffered saline is shown in Figure 6. After a 10-day degradation process, a rough irregular degraded surface was observed by SEM (Figure 6A). The surface of BBF-loaded PLLA nanoparticles became rougher and the spherical shape deformed after 20 days of degradation in phosphate-buffered saline (Figure 6B). As degradation proceeded, the BBF-loaded PLLA nanoparticles showed gradual loss of their spherical shape. The BBF-loaded PLLA nanoparticles showed only partial retention of their shapes due to degradation of the polymer after 30 days (Figure 6C). Surface degradation of the polymer was accompanied with a reduction in particle size. After 45 days of degradation in phosphate-buffered saline, the bulk of the BBF-loaded PLLA nanoparticles was degraded, leaving behind a shell-like polymer (Figure 6D). Degradation proceeded faster internally than externally in phosphate-buffered saline buffer due to internal build up of acidic byproducts that self-catalyze the degradation process, resulting in formation of hollow cores. ${ }^{42}$

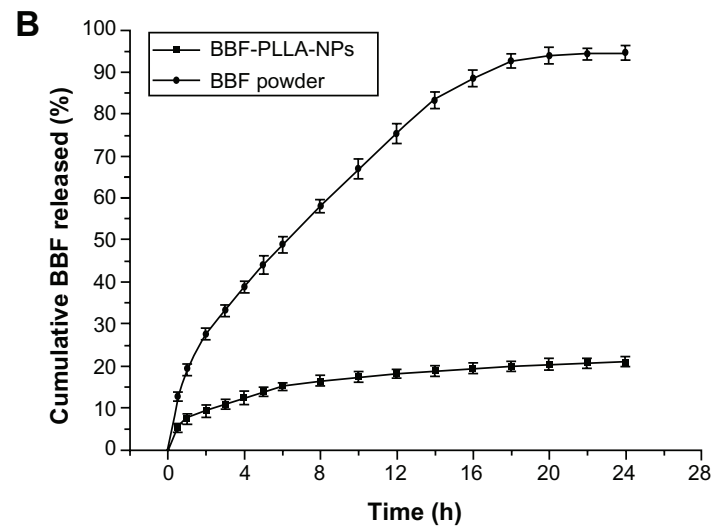

Figure 5 In vitro release curves for BBF from BBF-loaded PLLA nanoparticles and BBF powder in phosphate-buffered saline. (A) Experimental points over the complete time assay. (B) First 24 hours of the release study $(n=3)$.

Abbreviations: BBF, (Z-)-4-bromo-5-(bromomethylene)-2(5H)-furanone; PLLA, poly(L-lactic acid); NPs, nanoparticles. 


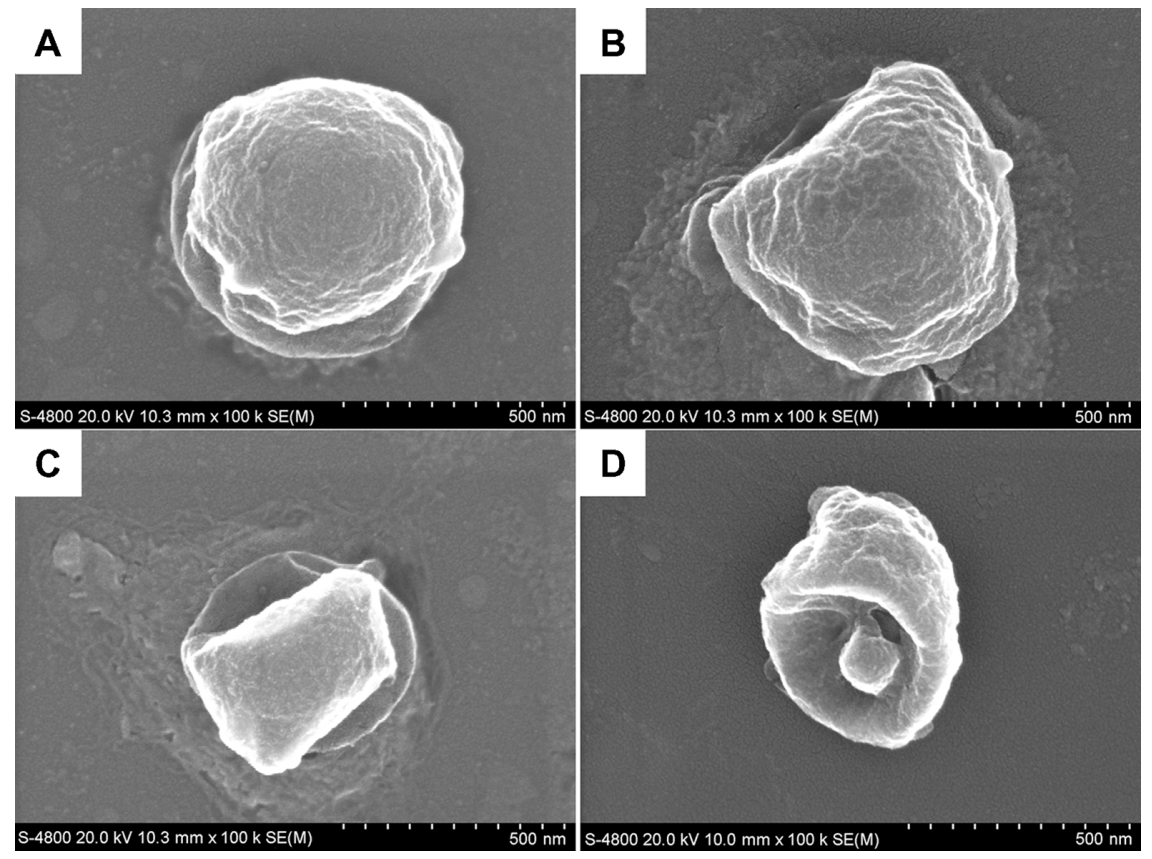

Figure 6 Scanning electron microscopic images of the degradation process of BBF-loaded PLLA nanoparticles in phosphate-buffered saline. (A) 10 days. (B) 20 days. (C) 30 days. (D) 45 days.

Abbreviations: BBF, (Z-)-4-bromo-5-(bromomethylene)-2(5H)-furanone; PLLA, poly(L-lactic acid).

Our morphological study results agreed with the BBF release curve from PLLA nanoparticles.

The PLLA nanoparticle degradation rate was related to environmental factors, including temperature and $\mathrm{pH}$. The $\mathrm{pH}$ of the phosphate-buffered saline in the release studies was checked after 2 months had elapsed, and was still within the range of 7.0-7.4. Therefore, the volume and buffering capacity of the phosphate-buffered saline were sufficient to diminish any effect of PLLA degradation on the $\mathrm{pH}$ of the degradation medium.

\section{Microarc oxidation}

Microarc oxidation was carried out using a pulsed direct current power supply. Figure 7 shows SEM images of the surface morphology of commercially pure titanium before and after microarc oxidation. The surface of the commercially pure titanium before microarc oxidation shows some parallel grooves oriented along the machined direction (Figure 7A). After microarc oxidation, a porous coating with pores $1-3 \mu \mathrm{m}$ in diameter distributed at regular intervals was observed (Figure 7B). The pores formed by oxygen bubbles in the coating growth process, could provide space for adhesion of nanoparticles in the next procedure. The surface phase composition of the microarc oxidation coating is shown in Figure 8. Peaks for anatase, rutile, and titanium were detected on the microarc-oxidized titanium.

Microarc oxidation coatings usually exhibit good adhesion to substrates, and the wear resistance, corrosion

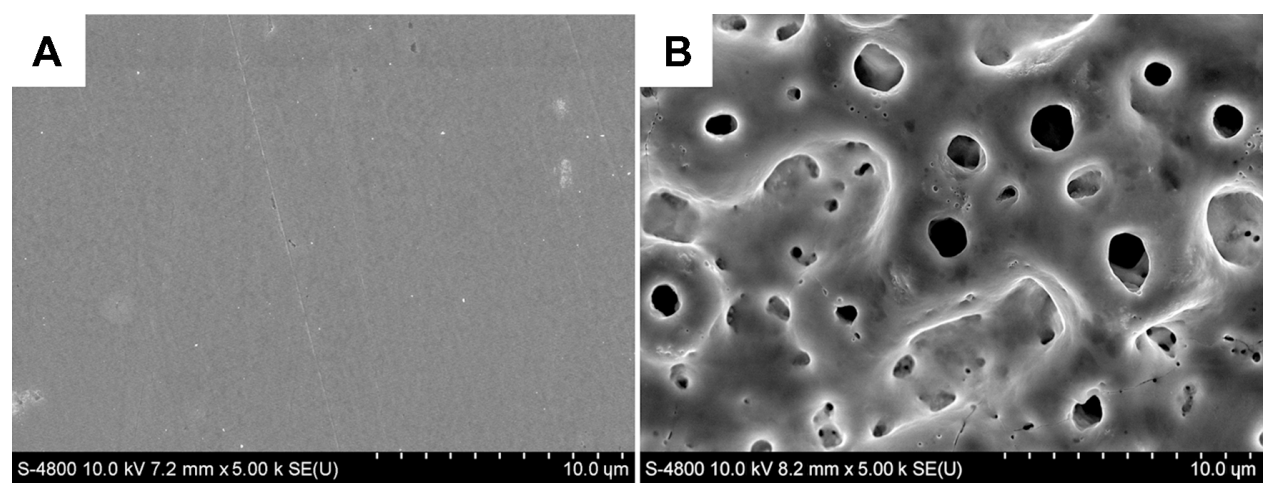

Figure 7 Scanning electron microscopic images of the surface morphology of commercially pure titanium (A) before and (B) after microarc oxidation. 


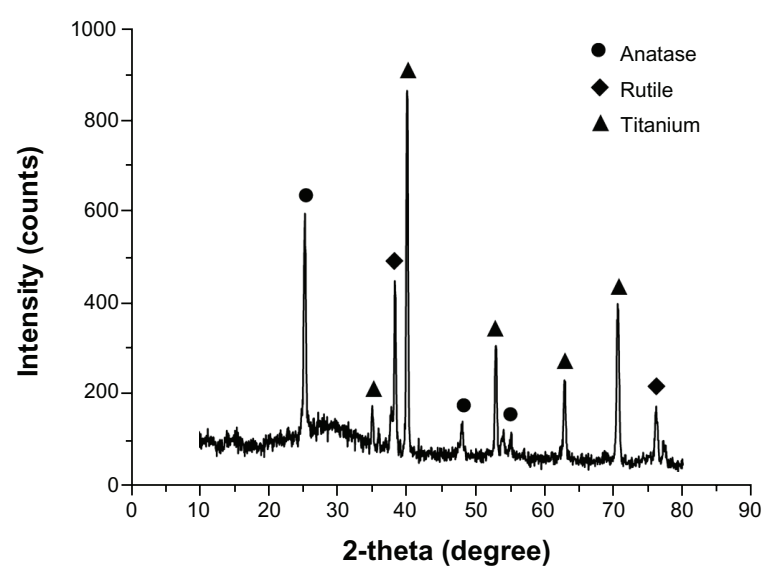

Figure $8 \times$-ray diffraction spectra of the surface phase composition of the microarc oxidation coatings.

resistance, and microhardness of the coating have greatly improved. ${ }^{35,36}$ Previous studies have confirmed that microarc oxidation coatings containing $\mathrm{Ca}$ and $\mathrm{P}$ show significantly increased hydrophilicity and roughness, which would be beneficial for cell attachment, propagation, and bone growth. ${ }^{43}$ Therefore, microarc oxidation is considered to be one of the best methods for modifying the titanium implant surface and improving its bioactive capability.

\section{Fabrication and surface morphology of antibacterial coating containing BBF-loaded PLLA nanoparticles on microarc-oxidized titanium}

The antibacterial coating was fabricated by cross-linking BBF-loaded PLLA nanoparticles successfully with gelatin on microarc-oxidized titanium. Figure 9 shows the surface morphology of an antibacterial coating containing BBFloaded PLLA nanoparticles on microarc-oxidized titanium. The pores on the surface of microarc-oxidized titanium were almost overlaid by the cross-linked nanospheres/ gelatin composite coating, and there were only a few nanospheres adherent to the flat areas between the pores due to the oscillating procedure during fabrication (Figure 9A), which would effectively prevent the antibacterial nanospheres from falling off during insertion of the dental implant. The BBF-loaded PLLA nanoparticles were well distributed in the pores of the microarc oxidation coating, and cross-linked with each other and the walls of the pores by gelatin (Figure 9B). This antibacterial coating had relatively high stability and binding capacity because it was integrated with the microarc oxidation coating by physical interlocking. ${ }^{39}$

\section{In vitro release study of BBF from the antibacterial coating}

Figure 10 shows the in vitro release profile for BBF from the antibacterial coating. It also shows a biphasic release phenomenon, which is similar to the release profile for BBF from the BBF-loaded PLLA nanoparticles. The initial burst release showed that $9.4 \%$ of the accumulated amount of BBF was slowly released from the antibacterial coating at the first sampling time of 4 hours. At the second stage of release, $80.8 \%$ of $\mathrm{BBF}$ was slowly released from the antibacterial coating during the next 60 days. However, compared with the release curves for BBF from BBFloaded PLLA nanoparticles, the cross-linked antibacterial coating showed a slightly lower initial burst release and a longer sustained release period. The results of the current study agree with previous research findings. ${ }^{39}$ It is thought that the presence of the cross-linked gelatin created a barrier for the surface-associated drug to diffuse into the phosphate-buffered saline, resulting in a lower initial burst release.

The morphological study of the degradation process for antibacterial coating in phosphate-buffered saline is
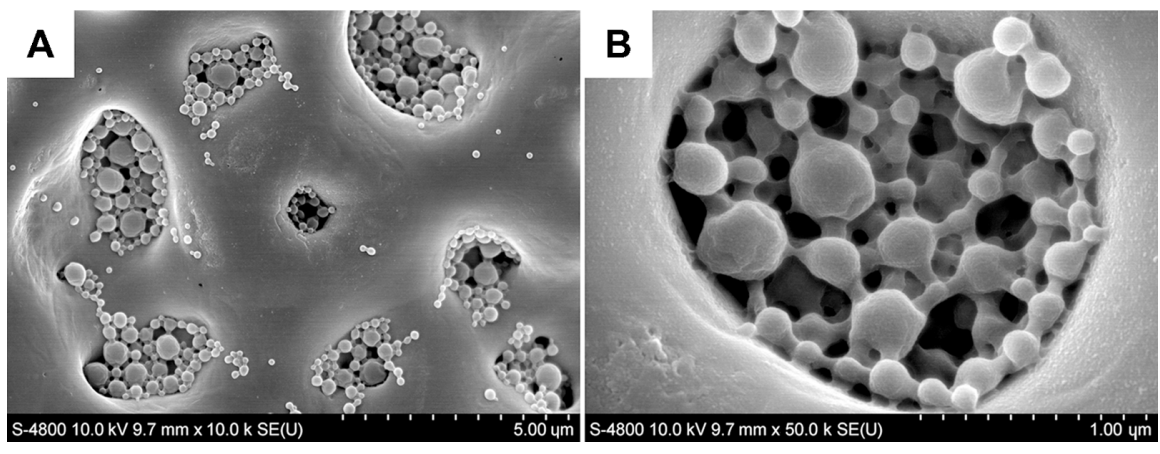

Figure 9 Scanning electron microscopic images of the antibacterial coating containing BBF-loaded PLLA nanoparticles on microarc-oxidized titanium. Antibacterial coating at low (A) and high (B) magnification.

Abbreviations: BBF, (Z-)-4-bromo-5-(bromomethylene)-2(5H)-furanone; PLLA, poly(L-lactic acid). 

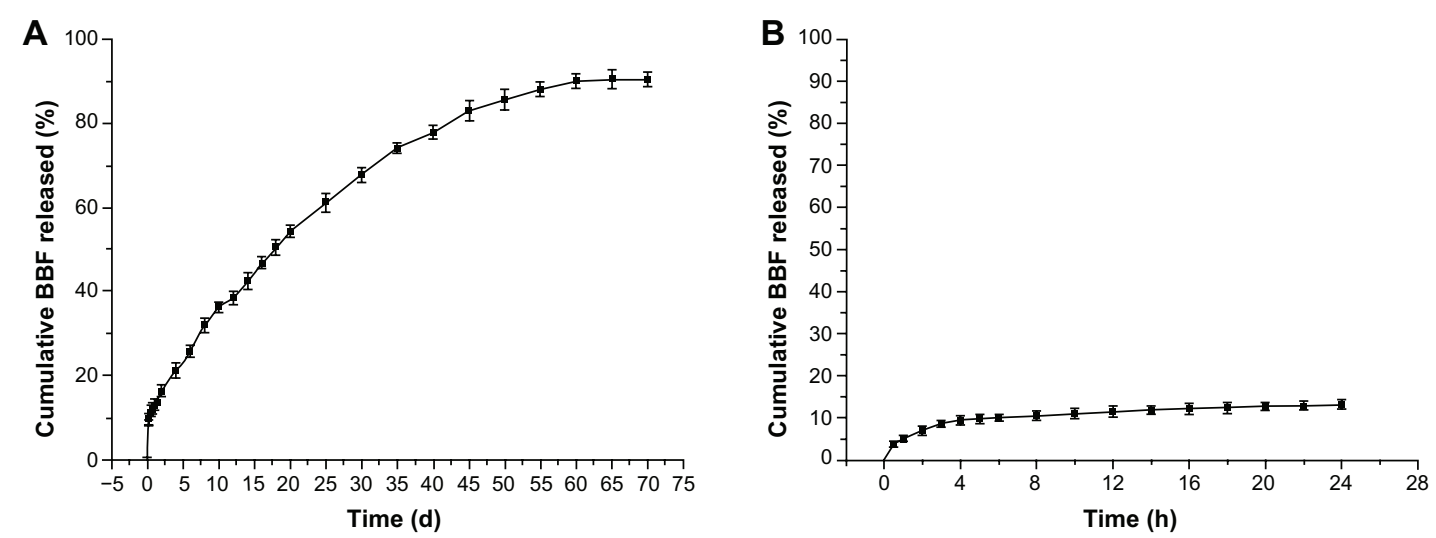

Figure 10 In vitro release curves for BBF from antibacterial coating containing BBF-loaded poly(L-lactic acid) nanoparticles on microarc-oxidized titanium. (A) Experimental points over the complete time assay. (B) First 24 hours for the release study $(n=3)$.

Abbreviation: BBF, (Z-)-4-bromo-5-(bromomethylene)-2(5H)-furanone.

shown in Figure 11. After a 15-day degradation process, some of the BBF-loaded PLLA nanoparticles in the fabricated antibacterial coating deformed from their spherical shape (Figure 11A). As degradation proceeded, some of the nanoparticles separated from the cross-linked gelatin due to external degradation after 30 days of immersion in the stirred phosphate-buffered saline (Figure 11B). Subsequently, the number of nanoparticles separating out increased (Figure 11C). After 60 days of degradation, there were only a few degraded nanoparticles and fragments remaining in the pores on the microarc-oxidized titanium (Figure 11D). These findings are consistent with the release curves for BBF from the antibacterial coating.

\section{Discussion}

Researchers in the past have used various methods to try and prevent bacterial adhesion on dental implants, including physical and chemical modification of the implant surface. Physical surface treatments to alter the surface properties are a relatively simple way to repel bacterial colonization. Annunziata et al demonstrated decreased bacterial (Streptococcus pyogenes and Streptococcus sanguinis) adhesion and proliferation on a tita-
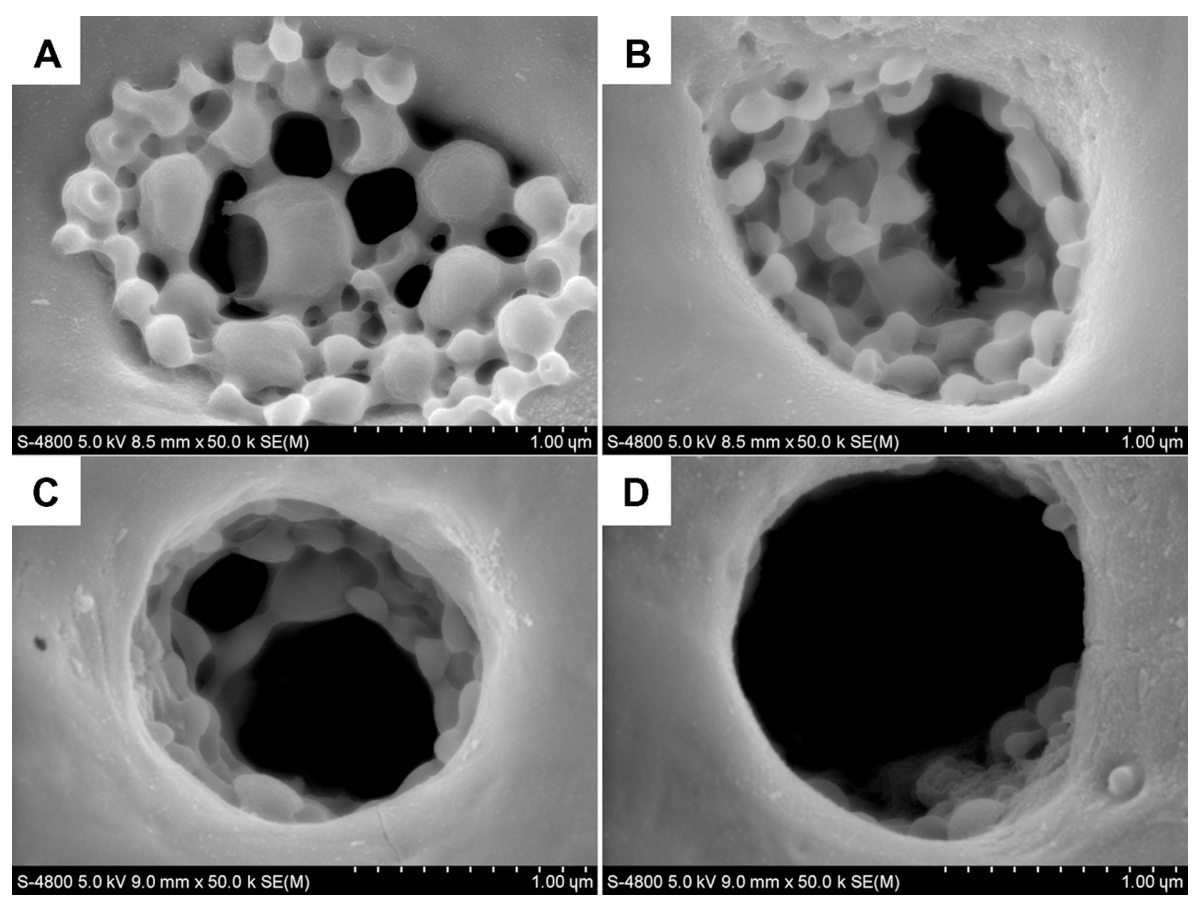

Figure II Scanning electron microscopic images of the degradation process for antibacterial coating containing BBF-loaded PLLA nanoparticles on microarc oxidationtreated titanium in phosphate-buffered saline. (A) 15 days. (B) 30 days. (C) 45 days. (D) 60 days.

Abbreviations: BBF, (Z-)-4-bromo-5-(bromomethylene)-2(5H)-furanone; PLLA, poly(L-lactic acid). 
nium nitride coating. ${ }^{44}$ However, more attention has been paid to the improved osseointegration effect of physical surface treatments. Antibacterial coatings have been traditionally designed to prevent initial adhesion of bacteria onto the implant surface. Many surface coatings containing or releasing antimicrobial agents, such as cephalothin, amoxicillin, gentamicin, tobramycin, and vancomycin, have been incorporated into implants with some success. ${ }^{45}$ Nevertheless, with the emergence of bacterial drug resistance, ${ }^{16,17}$ this form of therapy may be short-lived and may soon become ineffective. Additionally, several reports have pointed out that some antimicrobial agents may cause cell damage. ${ }^{46}$ Chlorhexidine has been widely used in dentistry as a treatment for periodontal infection because of its broad spectrum of antimicrobial action and low risk of drug resistance. Studies have shown that chlorhexidine can be absorbed onto the $\mathrm{TiO}_{2}$ layer on the titanium surface, but the gradual release period lasts only a few days. ${ }^{47}$ Silver has also been introduced onto titanium to enhance bactericidal ability, but the mechanism of bactericidal action needs further clarification. Therefore, using new effective antibacterial agents on implants and taking measures to ensure slow antibacterial release are essential in preventing early peri-implant infection.

Halogenated furanone compounds have been considered to be potentially ideal antibacterial agents on implants for preventing biofilm infection due to their broad spectrum antimicrobial activity, ${ }^{20,21}$ novel mechanisms of antimicrobial action, ${ }^{22}$ and lack of toxicity and genotoxic effects. ${ }^{25,26}$ The BBF used in this study is a member of the synthetic halogenated furanone family of compounds. Previous studies have indicated that BBF is one of the most active halogenated furanone compounds for inhibiting biofilm formation at low concentrations $(30-40 \mu \mathrm{M}){ }^{20}$ In the current study, a novel antibacterial coating containing BBF-loaded PLLA nanoparticles was fabricated on microarcoxidized titanium. The results of the BBF release study showed that the antibacterial coating could sustain release of $\mathrm{BBF}$ for 60 days, with a slight initial burst release during the first 4 hours. Quirynen et al suggested that initial colonization of peri-implant pockets with bacteria occurred within the first 2 weeks after dental endosseous implantation, and that the number of bacteria in peri-implant pockets increased afterwards (2-13 weeks). ${ }^{48}$ Therefore, the novel antibacterial coating fabricated in this study (sustaining release of BBF for 60 days) is a potentially promising method for prevention of early peri-implant infection and retrograde peri-implantitis, ${ }^{49}$ which would be necessary for long-term success.

Furthermore, our research group has evaluated the biocompatibility and antimicrobial activity of the fabricated antibacterial coating in vitro. Our results indicate that the antibacterial coating has excellent biocompatibility and potent antimicrobial activity against various conventional periodontal pathogens, such as Porphyromonas gingivalis, Actinobacillus actinomycetemcomitans, Prevotella intermedia, and Fusobacterium. These results will be reported in an upcoming publication. Our next step will be to investigate the biocompatibility and antimicrobial activity of the fabricated antibacterial coating in vivo.

\section{Conclusion}

In this study, a novel antibacterial coating containing BBFloaded PLLA nanoparticles was fabricated on microarcoxidized titanium. The morphology of the antibacterial coating showed that the BBF-loaded PLLA nanoparticles were well distributed and cross-linked with each other and the pore walls by gelatin. The release study indicates that the antibacterial coating could sustain release of BBF for 60 days, with a slight initial burst release during the first 4 hours. The novel antibacterial coating fabricated in this study is a potentially promising method for the prevention of early peri-implant infection.

\section{Acknowledgment}

This project was supported by a grant from the National Natural Science Foundation of China (51001116).

\section{Disclosure}

The authors report no conflicts of interest in this work.

\section{References}

1. Buser D, Mericske-Stern R, Bernard JP, et al. Long-term evaluation of non-submerged ITI implants. Part 1: 8-year life table analysis of a prospective multi-center study with 2359 implants. Clin Oral Implants Res. 1997;8:161-172.

2. Ekelund JA, Lindquist LW, Carlsson GE, Jemt T. Implant treatment in the edentulous mandible: a prospective study on Branemark system implants over more than 20 years. Int J Prosthodont. 2003;16:602-608.

3. Ferrigno N, Laureti M, Fanali S, Grippaudo G. A long-term follow-up study of non-submerged ITI implants in the treatment of totally edentulous jaws. Part I: Ten-year life table analysis of a prospective multicenter study with 1286 implants. Clin Oral Implants Res. 2002;13: 260-273

4. Simonis P, Dufour T, Tenenbaum H. Long-term implant survival and success: a 10-16-year follow-up of non-submerged dental implants. Clin Oral Implants Res. 2010;21:772-777.

5. Palma-Carrio C, Maestre-Ferrin L, Penarrocha-Oltra D, PenarrochaDiago MA, Penarrocha-Diago M. Risk factors associated with early failure of dental implants. A literature review. Med Oral Patol Oral Cir Bucal. 2011;16:e514-e517.

6. Schwartz-Arad D, Laviv A, Levin L. Failure causes, timing, and cluster behavior: an 8-year study of dental implants. Implant Dent. 2008;17: 200-207.

7. Lindhe J, Meyle J. Peri-implant diseases: consensus report of the sixth european workshop on periodontology. J Clin Periodontol. 2008;35: 282-285.

8. Heitz-Mayfield LJ. Peri-implant diseases: diagnosis and risk indicators. J Clin Periodontol. 2008;35:292-304. 
9. Quirynen M, De Soete M, van Steenberghe D. Infectious risks for oral implants: a review of the literature. Clin Oral Implants Res. 2002;13: $1-19$.

10. Pye AD, Lockhart DE, Dawson MP, Murray CA, Smith AJ. A review of dental implants and infection. J Hosp Infect. 2009;72:104-110.

11. Quirynen M, Teughels W. Microbiologically compromised patients and impact on oral implants. Periodontol 2000. 2003;33:119-128.

12. Mombelli A, van Oosten MA, Schurch EJ, Land NP. The microbiota associated with successful or failing osseointegrated titanium implants. Oral Microbiol Immunol. 1987;2:145-151.

13. Leonhardt A, Renvert S, Dahlen G. Microbial findings at failing implants. Clin Oral Implants Res. 1999;10:339-345.

14. Paster BJ, Boches SK, Galvin JL, et al. Bacterial diversity in human subgingival plaque. J Bacteriol. 2001;183:3770-3783.

15. Zhao L, Chu PK, Zhang Y, Wu Z. Antibacterial coatings on titanium implants. J Biomed Mater Res B Appl Biomater. 2009;91:470-480.

16. Feres M, Haffajee AD, Allard K, Som S, Goodson JM, Socransky SS. Antibiotic resistance of subgingival species during and after antibiotic therapy. J Clin Periodontol. 2002;29:724-735.

17. Prieto-Prieto J, Calvo A. Microbiological basis of oral infections and sensitivity to antibiotics. Med Oral Patol Oral Cir Bucal. 2004;9 Suppl: 11-18.

18. de Nys R, Givskov M, Kumar N, Kjelleberg S, Steinberg PD. Furanones. Prog Mol Subcell Biol. 2006;42:55-86.

19. Ren D, Bedzyk LA, Ye RW, Thomas SM, Wood TK. Differential gene expression shows natural brominated furanones interfere with the autoinducer-2 bacterial signaling system of Escherichia coli. Biotechnol Bioeng. 2004;88:630-642.

20. Janssens JC, Steenackers H, Robijns S, et al. Brominated furanones inhibit biofilm formation by Salmonella enterica serovar Typhimurium. Appl Environ Microbiol. 2008;74:6639-6648.

21. Kuehl R, Al-Bataineh S, Gordon O, et al. Furanone at subinhibitory concentrations enhances staphylococcal biofilm formation by luxS repression. Antimicrob Agents Chemother. 2009;53:4159-4166.

22. Ren D, Bedzyk LA, Ye RW, Thomas SM, Wood TK. Differential gene expression shows natural brominated furanones interfere with the autoinducer-2 bacterial signaling system of Escherichia coli. Biotechnol Bioeng. 2004;88:630-642.

23. Daniels R, Vanderleyden J, Michiels J. Quorum sensing and swarming migration in bacteria. FEMS Microbiol Rev. 2004;28:261-289.

24. Raffa RB, Iannuzzo JR, Levine DR, et al. Bacterial communication ("quorum sensing") via ligands and receptors: a novel pharmacologic target for the design of antibiotic drugs. J Pharmacol Exp Ther. 2005;312:417-423.

25. Baveja JK, Li G, Nordon RE, et al. Biological performance of a novel synthetic furanone-based antimicrobial. Biomaterials. 2004;25: 5013-5021.

26. Hume EB, Baveja J, Muir B, et al. The control of Staphylococcus epidermidis biofilm formation and in vivo infection rates by covalently bound furanones. Biomaterials. 2004;25:5023-5030.

27. Baveja JK, Willcox MD, Hume EB, Kumar N, Odell R, Poole-Warren LA. Furanones as potential anti-bacterial coatings on biomaterials. Biomaterials. 2004;25:5003-5012.

28. Lonn-Stensrud J, Landin MA, Benneche T, Petersen FC, Scheie AA. Furanones, potential agents for preventing Staphylococcus epidermidis biofilm infections? J Antimicrob Chemother. 2009;63:309-316.

29. Pancholi K. A review of imaging methods for measuring drug release at nanometre scale: a case for drug delivery systems. Expert Opin Drug Deliv. 2012;9:203-218.

30. Kashi TS, Eskandarion S, Esfandyari-Manesh M, et al. Improved drug loading and antibacterial activity of minocycline-loaded PLGA nanoparticles prepared by solid/oil/water ion pairing method. Int $J$ Nanomedicine. 2012;7:221-234.
31. Le Guehennec L, Soueidan A, Layrolle P, Amouriq Y. Surface treatments of titanium dental implants for rapid osseointegration. Dent Mater. 2007;23:844-854.

32. Guida L, Annunziata M, Rocci A, Contaldo M, Rullo R, Oliva A. Biological response of human bone marrow mesenchymal stem cells to fluoride-modified titanium surfaces. Clin Oral Implants Res. 2010;21: 1234-1241.

33. Mendonca G, Mendonca DB, Aragao FJ, Cooper LF. Advancing dental implant surface technology - from micron- to nanotopography. Biomaterials. 2008;29:3822-3835.

34. Annunziata M, Oliva A, Buosciolo A, Giordano M, Guida A, Guida L. Bone marrow mesenchymal stem cell response to nano-structured oxidized and turned titanium surfaces. Clin Oral Implants Res. 2012;23: 733-740.

35. Wang YM, Jiang BL, Lei TQ, Guo LX. Microarc oxidation coatings formed on Ti6Al4V in $\mathrm{Na}_{2} \mathrm{SiO}_{3}$ system solution: microstructure, mechanical and tribological properties. Surf Coat Technol. 2006;201: 82-89.

36. Yao ZP, Jiang ZH, Wu XH, Sun XT, Wu ZD. Effects of ceramic coating by micro-plasma oxidation on the corrosion resistance of Ti-6Al-4V alloy. Surf Coat Technol. 2005;200:2445-2450.

37. Wu J, Liu ZM, Zhao XH, Gao Y, Hu J, Gao B. Improved biological performance of microarc-oxidized low-modulus Ti-24 Nb-4Zr-7.9Sn alloy. J Biomed Mater Res B Appl Biomater. 2010;92:298-306.

38. Wei D, Zhou Y, Jia D, Wang Y. Characteristic and in vitro bioactivity of a microarc-oxidized $\mathrm{TiO}(2)$-based coating after chemical treatment. Acta Biomater. 2007;3:817-827.

39. Xu XH, Lu P, Guo MQ, Fang MZ. Cross-linked gelatin/nanoparticles composite coating on micro-arc oxidation film for corrosion and drug release. Appl Surf Sci. 2010;256:2367-2371.

40. Yoshizawa H, Nishino S, Shiomori K, Natsugoe S, Aiko T, Kitamura Y. Surface morphology control of polylactide microspheres enclosing irinotecan hydrochloride. Int J Pharm. 2005;296:112-116.

41. Lee JW, Gardella JJ, Hicks WJ, Hard R, Bright FV. Analysis of the initial burst of drug release coupled with polymer surface degradation. Pharm Res. 2003;20:149-152.

42. Fu K, Pack DW, Klibanov AM, Langer R. Visual evidence of acidic environment within degrading poly(lactic-co-glycolic acid) (PLGA) microspheres. Pharm Res. 2000;17:100-106.

43. Lim YW, Kwon SY, Sun DH, Kim HE, Kim YS. Enhanced cell integration to titanium alloy by surface treatment with microarc oxidation: a pilot study. Clin Orthop Relat Res. 2009;467:2251-2258.

44. Annunziata M, Oliva A, Basile MA, et al. The effects of titanium nitride-coating on the topographic and biological features of TPS implant surfaces. J Dent. 2011;39:720-728.

45. Stigter M, Bezemer J, de Groot K, Layrolle P. Incorporation of different antibiotics into carbonated hydroxyapatite coatings on titanium implants, release and antibiotic efficacy. J Control Release. 2004;99: 127-137.

46. Ince A, Schutze N, Hendrich C, Jakob F, Eulert J, Lohr JF. Effect of polyhexanide and gentamycin on human osteoblasts and endothelial cells. Swiss Med Wkly. 2007;137:139-145.

47. Kozlovsky A, Artzi Z, Moses O, Kamin-Belsky N, Greenstein RB. Interaction of chlorhexidine with smooth and rough types of titanium surfaces. J Periodontol. 2006;77:1194-1200.

48. Quirynen M, Vogels R, Peeters W, van Steenberghe D, Naert I, Haffajee A. Dynamics of initial subgingival colonization of 'pristine' peri-implant pockets. Clin Oral Implants Res. 2006;17:25-37.

49. Quirynen M, Vogels R, Alsaadi G, Naert I, Jacobs R, van Steenberghe D. Predisposing conditions for retrograde peri-implantitis, and treatment suggestions. Clin Oral Implants Res. 2005;16:599-608. 


\section{Publish your work in this journal}

The International Journal of Nanomedicine is an international, peerreviewed journal focusing on the application of nanotechnology in diagnostics, therapeutics, and drug delivery systems throughout the biomedical field. This journal is indexed on PubMed Central, MedLine, CAS, SciSearch $\AA$, Current Contents ${ }^{\circledR} /$ Clinical Medicine,

Journal Citation Reports/Science Edition, EMBase, Scopus and the Elsevier Bibliographic databases. The manuscript management system is completely online and includes a very quick and fair peer-review system, which is all easy to use. Visit http://www.dovepress.com/ testimonials.php to read real quotes from published authors.

Submit your manuscript here: http://www.dovepress.com/international-journal-of-nanomedicine-journal 